\title{
DISTRIBUTED ENERGY SYSTEMS MANAGEMENT USING THE CASE BASED REASONING
}

\author{
El Yasmine Ait Si Larbi ${ }^{1{ }^{*},}$, Ghalem Belalem ${ }^{2}$ and Bouziane Beldjilali ${ }^{3}$ \\ ${ }^{1,2,3}$ Computer Science Laboratory of Oran (LIO), \\ Department of Computer Science, Faculty of exact and applied sciences, \\ University of Oran1 Ahmed Ben Bella, BP. 1524 El Mnaouer, Oran, Algeria \\ 1aitsilarbi@gmail.com, ${ }^{2}$ ghalem1dz@gmail.com, ${ }^{3}$ bouzianebeldjilali@yahoo.fr
}

\begin{abstract}
Regarding continued growth in the use of electrical energy, it is important to meet the final customer demand. In a smart grid context, there are several ways to do this. One of means is to add energy storages and infrastructures. We are so interested in this study to the modification of electrical infrastructures. By adapting organizations, managers and their teams must have the adequate behavior and decision making to modify existing materials or add new materials into the existing system. This paper shows a company team's behavior which operates in the field of energy supplying. The purpose of this paper is to show how teams' managers can use a past experience, and to evaluate the impact of structure modification according to decision making using the case based reasoning. The experiments concern more precisely the quantitative aspect of exchanged messages between managers and their teams.
\end{abstract}

Keywords - Control system, distributed energy system (DES), energy provider company, elasticity, interaction, decision making, electrical energy, flexibility, case based reasoning

\section{INTRODUCTION}

Smart grid, known as intelligent grid, is a growing concept in the electrical energy context, and takes a considerable place in research. Several studies have dealt with this concept, we cite [1] who illustrate in their paper why electricity smart grids should be seen as part of overall smart energy systems and emphasises the inclusion of flexible combined heat and power production in the electricity balancing and grid stabilisation. Likewise, in reference [2], authors present a review of communication/ networking technologies in smart grid, including communication/networking issues. We also have reference [3] where authors propose a distributed energy management approach that aims to manage residential energy by considering the neighborhood energy surpluses in order to decrease energy costs.

To achieve the intelligence of an electrical grid, energy providers companies face many constraints, like the increasing number of end users, constraints related to the dynamic company's environment and types of electrical networks included in electrical grids and finally, their distributed structure.

Received: April 14, 2019

Reviewed: June 3, 2019

Accepted: June 7, 2019

* Corresponding Author 
So, a company must be flexible and has to be in continuous progress and in constant dynamics with its environment; it must be able to adapt its structure to meet needs.

It is notable that distributed energy system (DES) has successfully aroused increasing interests among energy policy makers and system designers, as its potential of replacing conventional energy systems [4].

In this paper, we are interested in companies providing the electrical energy to end users; in this context, it is necessary to take into account the need of collaboration between different partners and to propose solutions in the aim to help managers to take decisions to solve problems that can arise in the electrical grids.

The main purpose of this article is to present a control system including a decision module using the case based reasoning; it will lead to solutions taken by managers, when there is a need to increase in energy supplying.

We specify that the notion of elasticity could be measured according to interzonal interactions [5]. From this statement, our idea is to evaluate the elasticity of the distributed company. In this way, we take into account the communication between different teams working in the energy providing domain. In fact, a performance of a system can be measured in terms of technological, economic, social and environmental aspects. So, to judge the impact of the presented approach, we use in this paper the number of stakeholders and the number of exchanged messages between teams' members, we can therefore appreciate the elasticity of the company from both of functional and structural point of view.

Regarding to the distributed structure of such companies, we propose the use of a multi agent system in the aim of simulating the behaviors of teams' members' of an electrical energy provider company.

In the goal to clarify our contribution, section 2 deals with the state of art concerning the elasticity concept and the case based reasoning method; section 3 concerns the context of energy providing and some principles; in section 4, the proposed contribution and a discussion about results obtained are presented. The last section concerns the conclusion and some eventual future works.

\section{RELATED WORKS}

\subsection{THE ELASTICITY CONCEPT}

Many definitions can be attributed to elasticity according to the area of use. By making the analogy between electrical grids and the cloud structure, end users can be the users, nodes can be servers and a grid can be a cluster, we can so retain the definition given in [6] specifying that an application is elastic if it adapts its rate according to the network conditions, it is inelastic if it does not.

There are many works in literature that deal with the notion of elasticity, we can cite [4], where the authors treat the subject of Distributed energy systems (DES), they present a review of district load forecasting (DLF) models to support the application of DES.

Also, in [7], the authors propose a model for the variations of the failure rate and compare the availability performance of an UPS (Uninterruptible Power Supply) based on a single core control board with a distributed UPS with on multiprocessor control boards.

According to [8], only when heterogeneity is assumed Pareto-distributed do all elasticities collapse into a unique elasticity.

In [9], authors confirm the persistence of low own-price elasticities both for diesel and gasoline in the short and long runs, their study concerns calculation of the price 
and income responsiveness of Spanish consumers of transport fuels, with an exploration of the recent economic crisis effects.

Also, in [10], authors detail how a deployment on a popular public cloud offering can be instrumented to gain insight into system characteristics such as capacity, scalability, elasticity and efficiency.

The KPI are used to quantify the performance of an energy provider system, in this context, many researches are made, in [11], and in the cloud computing context, elasticity is considered as a key property, according to authors, there is a lack of standard elasticity metrics or analysis procedures to easily quantify this performance of cloud services. This absence of a unique general elasticity metric makes difficult to consider elasticity as a service level objective in service level agreements, so, in the same paper, elasticity metric is proposed, capable of considering scalability, accuracy, time and cost, independently of the service level.

In [12], the authors talk about modeling of distributed systems. In the paper, many mechanisms are cited like the physical containment, the local and remote access rights on system resources.

The next sub section present the case based reasoning concept and its use in different works.

\subsection{CASE BASED REASONING:}

Case-based reasoning is a method of solving a current problem by studying the solutions to previous, similar problems. Many definitions could be found in the literature, we have retained that of [13], who states that the case-based reasoning is a psychological theory of human cognition.

For decades, case-based reasoning has been cited and used in several references, we can cite [14] who presents an introduction to the case-based reasoning process, and include an example of the creation and consultation use of the case base. The key concepts in case-based reasoning are discussed.

Also, [15] present a survey of fundamental issues and approaches in indexing and retrieval, situation assessment and similarity assessment. The case studies presented involve a sampling of tasks, such as design, legal reasoning, planning, and decision support.

[16] present a CBR approach for inert energy management systems that aims to reduce energy wastage in overheating and over cooling for buildings.

Also, [17] present an agent approach deployed in a Cloud environment with a wireless sensor network, in the goal to achieve energy savings; where the agents of the MAS learn social behavior thanks to the collection of data and the use of an artificial neural network.

In reference [18], authors propose the development of a knowledge-based system which integrates environmental factors into the supplier selection process. The system employs both case-based reasoning (CBR) and decision support components including multi-attribute analysis.

Concerning the case based reasoning used for flexibility, we have the work of [19] who propose an integrated framework based on multi-agent collaboration and case-based reasoning that can resolve many collaboration issues in the supply chain.

In the reviewed literature, we did not find any contribution that could solve the problem of electrical energy supplying using the case based reasoning.

In the next section, the global structure of energy provider companies is presented. 


\section{ENERGY PROVIDER COMPANIES' STRUCTURE}

We remain that we interest in a distributed company which provide the electrical energy. Figure 1 shows a general structure of a distributed energy provider company.

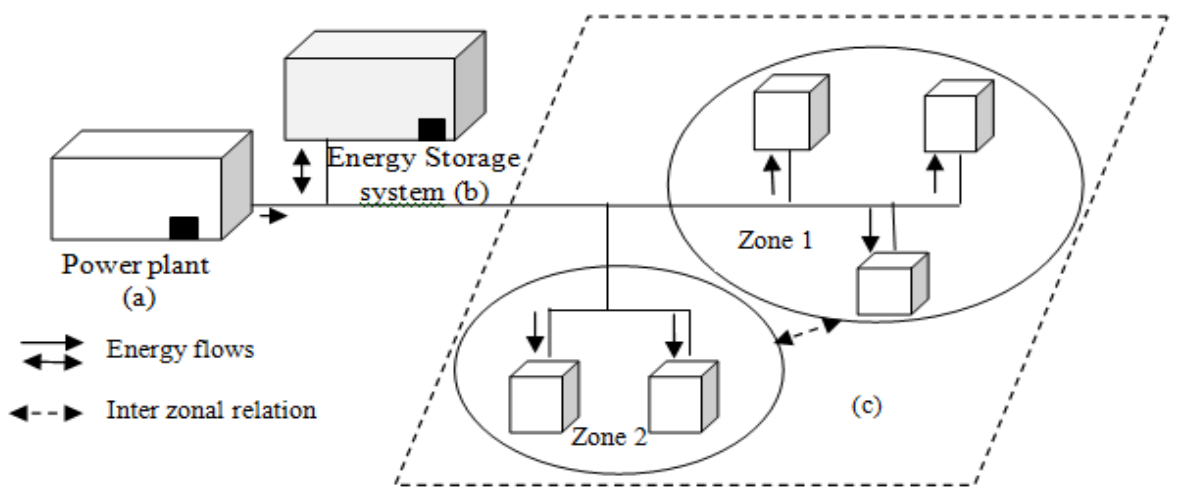

Fig. 1 Global structure of an electrical energy provider company

In Figure 1, there are three parts:

a) Many systems and technologies extract energy resources and convert them into electric energy in the aim to deliver them to end users to provide desired services such as manufacturing. There are many pathways to produce electricity, with the generation mix currently dominated by coal, natural gas, and nuclear resources.

b) Energy produced at time $t_{0}$ is captured for use at time $t 1$, where $t_{0}<t_{1}$.

c) Inter- zonal flows can be information shared and products or services exchanging between zones of the energy provider company. Each zone corresponds to a sub organization of the company.

It is notable that there are three types of electrical network according to the voltage that traverse lines, as it is shown in Figure 2, where HV/MV Transformer corresponds to High Voltage/ Medium Voltage transformer. MV/LV transformer corresponds to Medium voltage/ Low Voltage transformer.

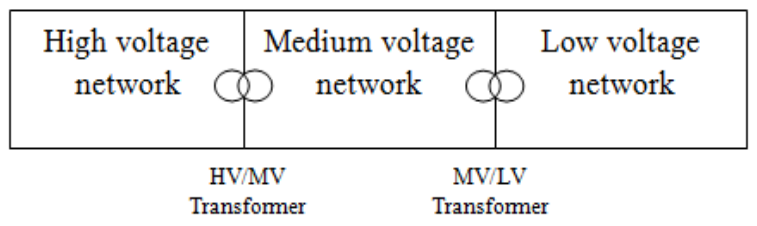

Fig. 2 Different Voltages in an Electrical Network

The low voltage is defined by the International Electrotechnical Commission (IEC) as a set of voltage levels used for the electricity distribution; the upper limit is generally accepted to be $1000 \mathrm{~V}$ for alternating current [20].

Low voltage networks are geographically situated in urban zones. High voltage zones are proximally to the power plant area.

Also, the global energy interconnection (GEI) symbolize high-level integration of the energy flow, information flow and flow of business as an intelligent, automated and networked-based system for ensuring energy security on a universal scale [21].

There are different types of structure of an electrical system, we can cite: mesh structure (1), radial structure (2) and tree structure (3) as it is shown in figure 3. 

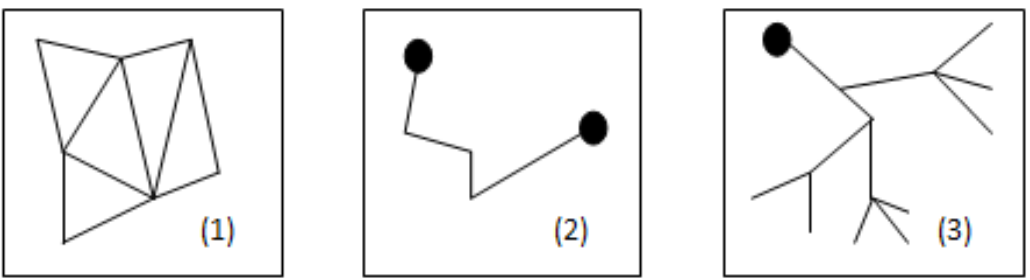

Fig. 3 Different structures of an electrical system

(1): the nodes are interconnected by power lines, providing good electrical energy supply continuity.

(2): the electrical energy supply continuity is less than in the first structure.

(3): the continuity of electrical energy supply is weak since a fault on the line or on the root station cuts all users. In this context, [22] propose an algorithm to balance such a network, where a node forward data to its children. Like diffusion of data, in electric energy diffusion, it is important to be able to repair the diffusion tree to allow an efficient energy distribution when node degrees are bounded. This constraint will be taken into account in this paper.

In reference [23], the authors proposed a mapping of supply chain structures using three primary attributes: members of the supply chain, structural dimensions, and types of business processes between the members.

The electric energy is distributed across lines in the network, which is considered as an electrical system and can take several states:

- Normal state: if the energy supply and operating constraints are satisfied.

- Emergency state: if the operating constraints are not met; it appears in the cases of line faults, overload, loss of synchronism, disconnection of materials ...etc. It can be caused by major disturbances that take system variables outside their limits.

- Alert state when the energy supply constraint is not fully respected and the network manager's actions carried out by the network control tools are effective.

- Extreme state when many or all loads are not supplied, i.e., an interruption of service or a generalized blackout can arise [24].

The next section will present the contribution.

\section{CONTRIBUTION}

\subsection{PROPOSED APPROACH MODELING}

When we have a new system, there is a need of energy monitoring, so, the electrical energy provider company must adapt its structure and behavior.

In electrical power global system management, there is a need of taking into account processes from generation, transmission, and distribution to sale (see Fig. 1).

The objective of an electric energy system is that consumers must be supplied with power, when the system variables (frequency and power) are included into the permitted intervals. Information concerning each electrical site is presented in Table I: 
Table I. Electrical Site Characteristics

\begin{tabular}{|c|c|c|}
\hline & Static information & Dynamic information \\
\hline Site name & $\mathrm{x}$ & \\
\hline Site code & $\mathrm{x}$ & \\
\hline Site type & $\mathrm{x}$ & $\mathrm{x}$ \\
\hline indoor temperature & & $\mathrm{x}$ \\
\hline outdoor temperature & $\mathrm{x}$ & $\mathrm{X}$ \\
\hline Load consumption & $\mathrm{x}$ & \\
\hline Grid Type & $\mathrm{x}$ & \\
\hline Supplier & $\mathrm{x}$ & \\
\hline Zone & & $\mathrm{X}$ \\
\hline Battery type & Low, medium, high voltage) & \\
\hline Consumed fuel & & \\
\hline
\end{tabular}

It is supposed that for each zone containing many sites, there is a team directed by a manager. Also, in each site, there is an engineer and a maintainer as it is shown in figure 4.

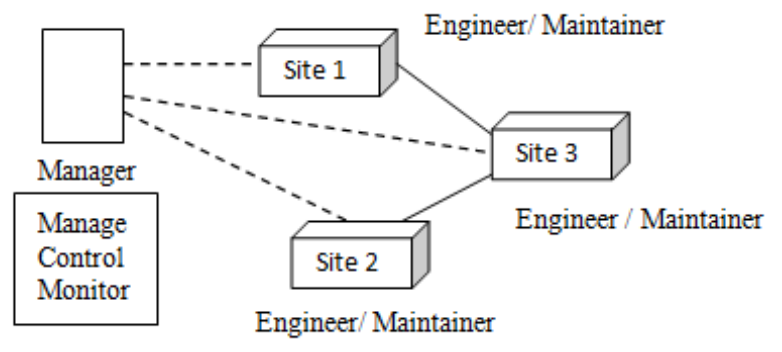

Fig. 4 Energy Operation Team

We use UML (Unified Modeling Language) to represent the system description. Fig. 5 shows Class diagram to understand static relations in a team.

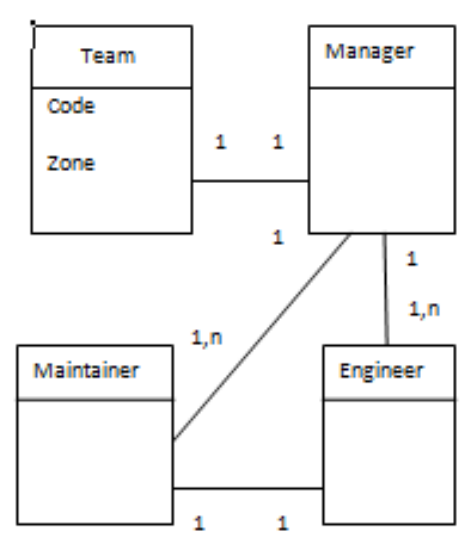

Fig. 5 Class Diagram of a Team

In the goal of understanding team mission, Figure 6 shows the role of each stakeholder in the system: 


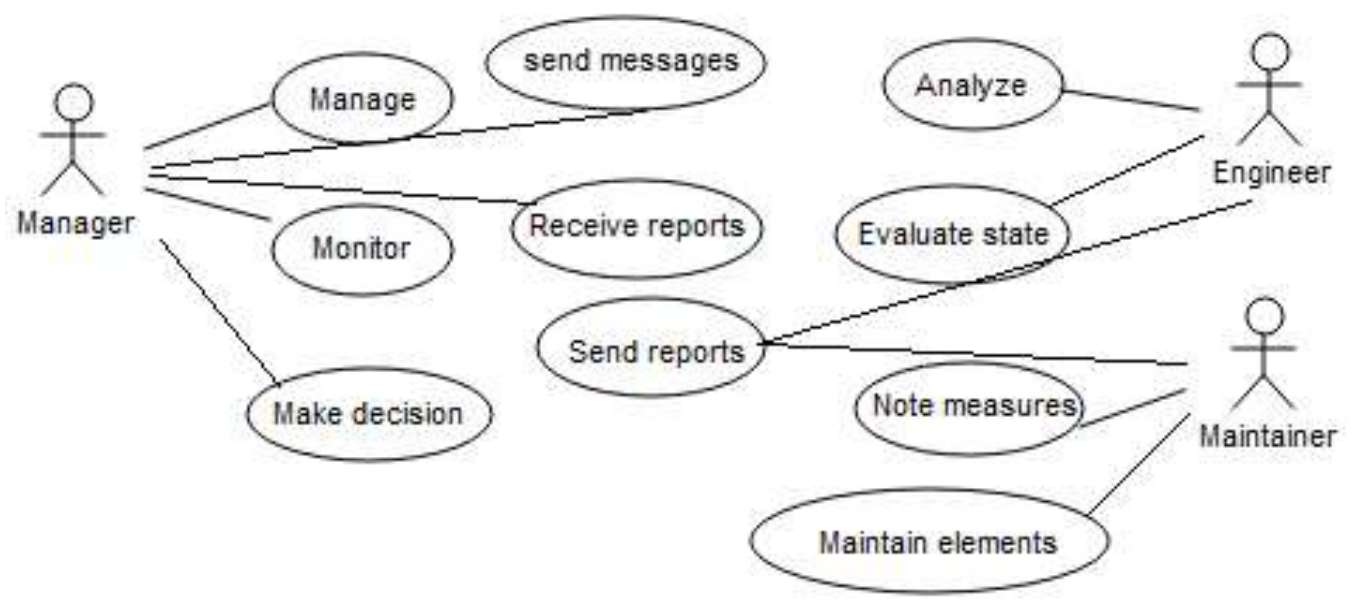

Fig. 6 Use Case Diagram for the Stakeholders of a Zone Team

The UML Sequence diagram presented in Figure 7 shows the managers interaction before decision making.

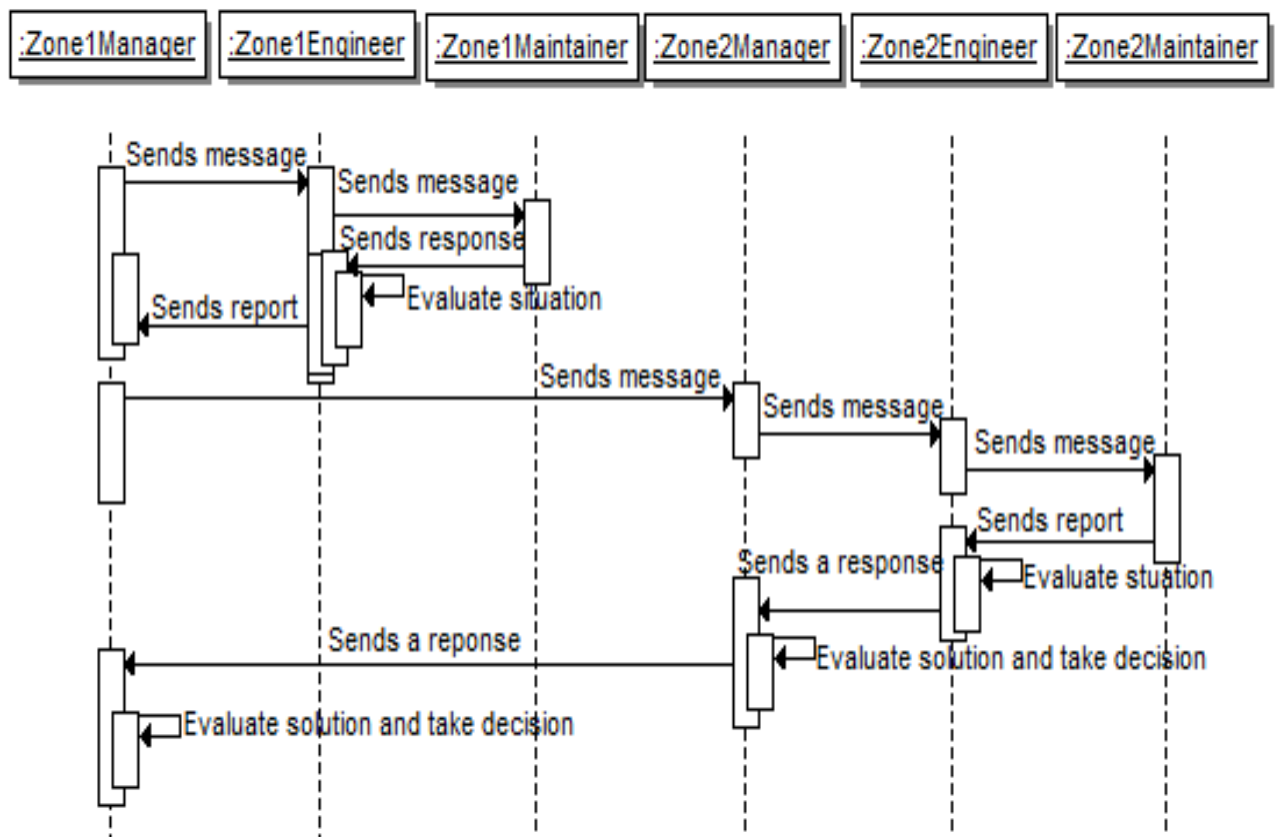

Fig. 7 Sequence Diagram of Managers' Interaction

The next sub section shows the explanation of the reasoning process.

\subsection{CASE BASED REASONING}

We suppose that we have zone 1 where there is need of more electrical energy supply because of increasing electricity consumption. As it is shown in Figure 8, the root node represents the power plant; site 1 (node 1 ) is the one that requires more electricity supply. 


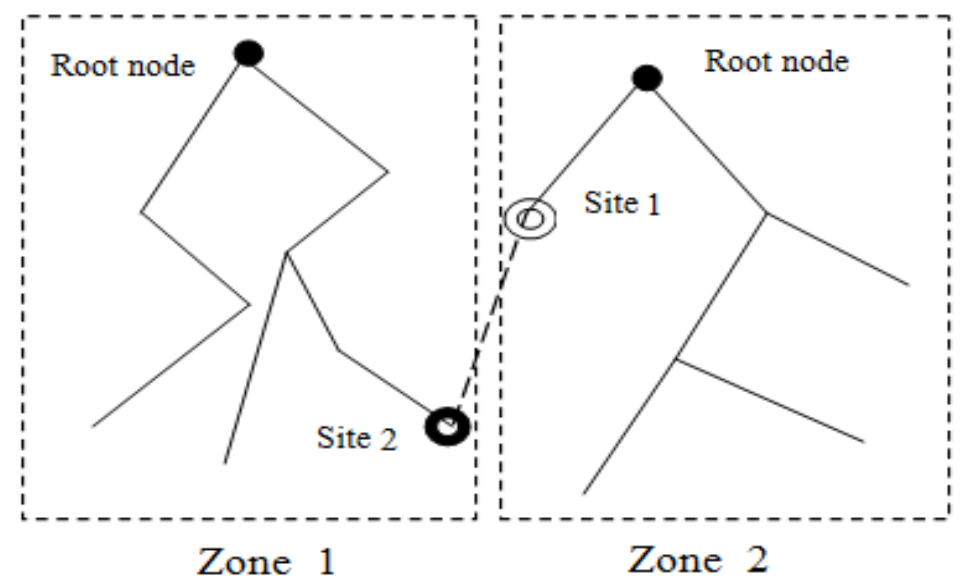

Fig. 8 Electrical connexion between zones

\subsubsection{CASE BASED REASONING MODULE FOR THE MANAGER AGENT:}

Each manager agent take decision after following a case based reasoning.

According to [25], the CBR is a methodology, not a technology. Where this methodology must fulfill four different activities, how these activities should be fulfilled is not specified which means that one CBR system can differ from another, Figure 9 shows the base based reasoning module for each manager agent.

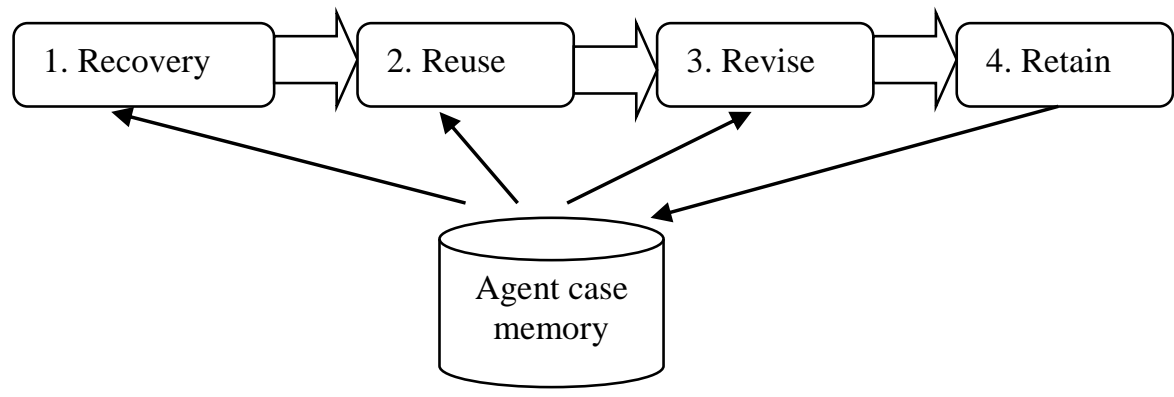

Fig. 9 CBR Manager Agent Module

The reasoning process for each manager agent follows four steps:

1. Recovery: Case recovery.

2. Reuse: Case which is similar.

3. Revise: The case is revised to find out if it corresponds to the expectations.

4. Retain: The solution could be retained or not.

A case memory is used to obtain similar cases and treat them.

In case based reasoning, a case is an experience represented by an acquaintance. This experience is a lesson that allows the RAC system to solve problems of different kinds. Depending on the area of application and the objectives to be attained, the information contained in the case varies. A case can be defined as the computer description of an episode of problem solving.

In CBR, we have two types of cases: source case and target case. The source case is the one in which the "problem" and "solution" parts are filled in. So, this is a case that will inspire us to solve a new problem.

As samples, we take into account two major different source cases that could appear in an electrical grid: 


\subsubsection{CASE 1:}

\section{Problem description:}

The two sites have the same voltage but a different courant type (AC (Alternative Courant) and DC (Direct Courant)).

Here, the company manager (or managers) must use High-voltage direct current (HVDC) transmission systems to connect the two separate high voltage AC systems using a DC link.

The HVDC system functioning is based on the conversion of AC to DC and DC to $\mathrm{AC}$ by means of converter valves.

In the case of an AC input courant, a rectifier is used to obtain a DC output courant. In the case of DC input courant, an inverter is used to obtain an AC output courant.

Figure 10 shows this scenario where there are two choices: A and B according to the geographic implantation of the converter station.

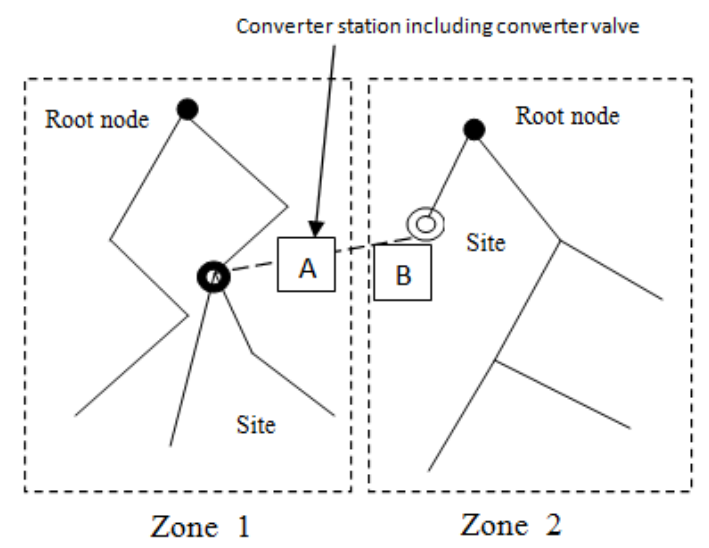

Fig. 10 Implantation of the converter station in case 1

\section{Solution description:}

Table II shows parameters used in decision making:

Table II. Parameters Used in Decision Making

\begin{tabular}{|c|l|}
\hline Parameter & \multicolumn{1}{|c|}{ Description } \\
\hline ACT & Acquisition Cost of Transformer \\
\hline ICT & Installation Cost of Transformer \\
\hline CC & Cost of Connection \\
\hline TCT 1 & Transportation costs of transformer from supplier of zone 1 \\
\hline TCT 2 & Transportation costs of transformer from supplier of zone 2 \\
\hline ACR & Acquisition Cost of Rectifier \\
\hline ACI & Acquisition Cost of Inverter \\
\hline TCR & Transportation Cost of Rectifier \\
\hline TCI & Transportation Cost of Inverter \\
\hline ICR & Installation Cost of Rectifier \\
\hline ICI & Installation Cost of Inverter \\
\hline MA & Maintainer Availability (Boolean) \\
\hline SA & Space Availability (m2) \\
\hline
\end{tabular}


The decision making is made according to minimization of the following costs:

In case of rectifier use, formula 1 is used:

$$
\text { Cost } 1 z_{n}=A C R+T C R+I C R+C C
$$

In the case of inverter use, formula 2 is used:

$$
\text { Cost } 2 z_{n}=A C I+T C I+I C I+C C
$$

Where $\mathrm{n}$ is the zone code.

Decision taken for the case 1 is as it is shown in Figure 11.

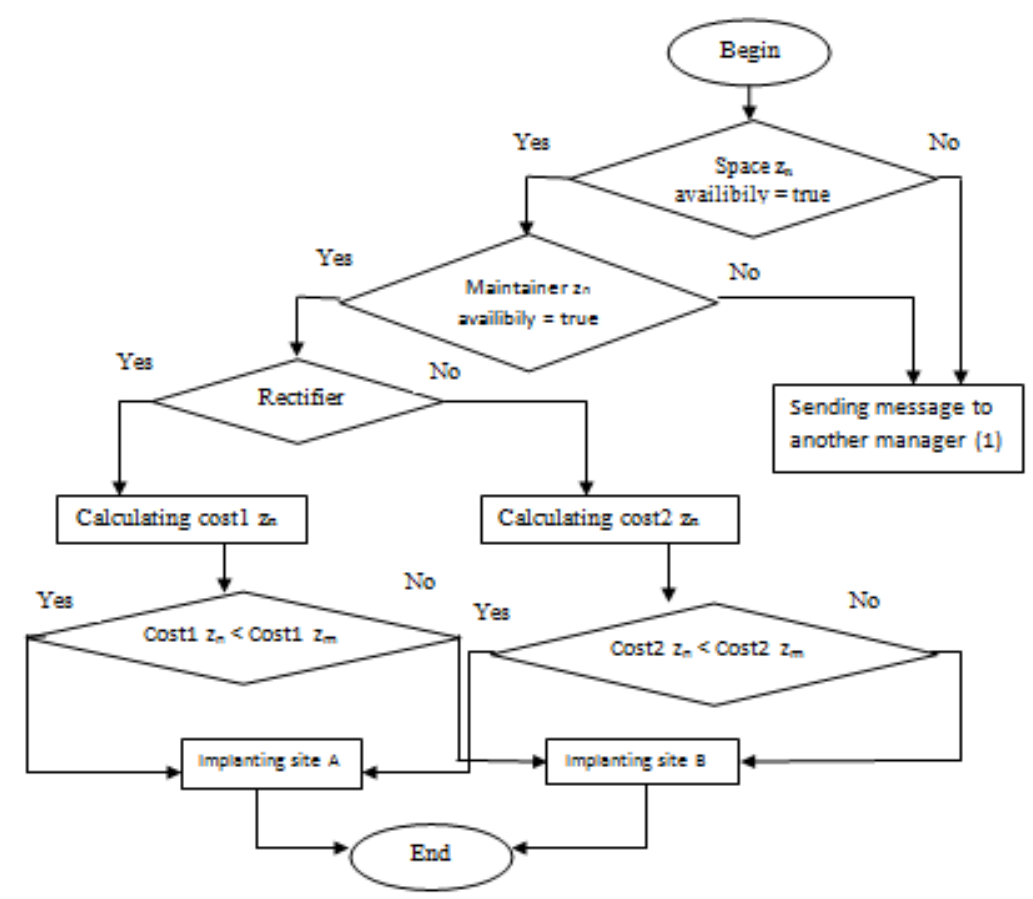

Fig. 11 Decision Process Corresponding to the First Case

\subsubsection{CASE 2: THE TWO ZONES HAVE DIFFERENT VOLTAGE:}

\section{Problem description:}

Here managers must manage a Back-to-back system: two independent systems having different and incompatible electrical parameters (frequency/voltage, level/short-circuit power level). They must be connected using a transformer and a AC/DC link.

\section{Solution description}

Figure 12 shows the decision process for the case 2: 


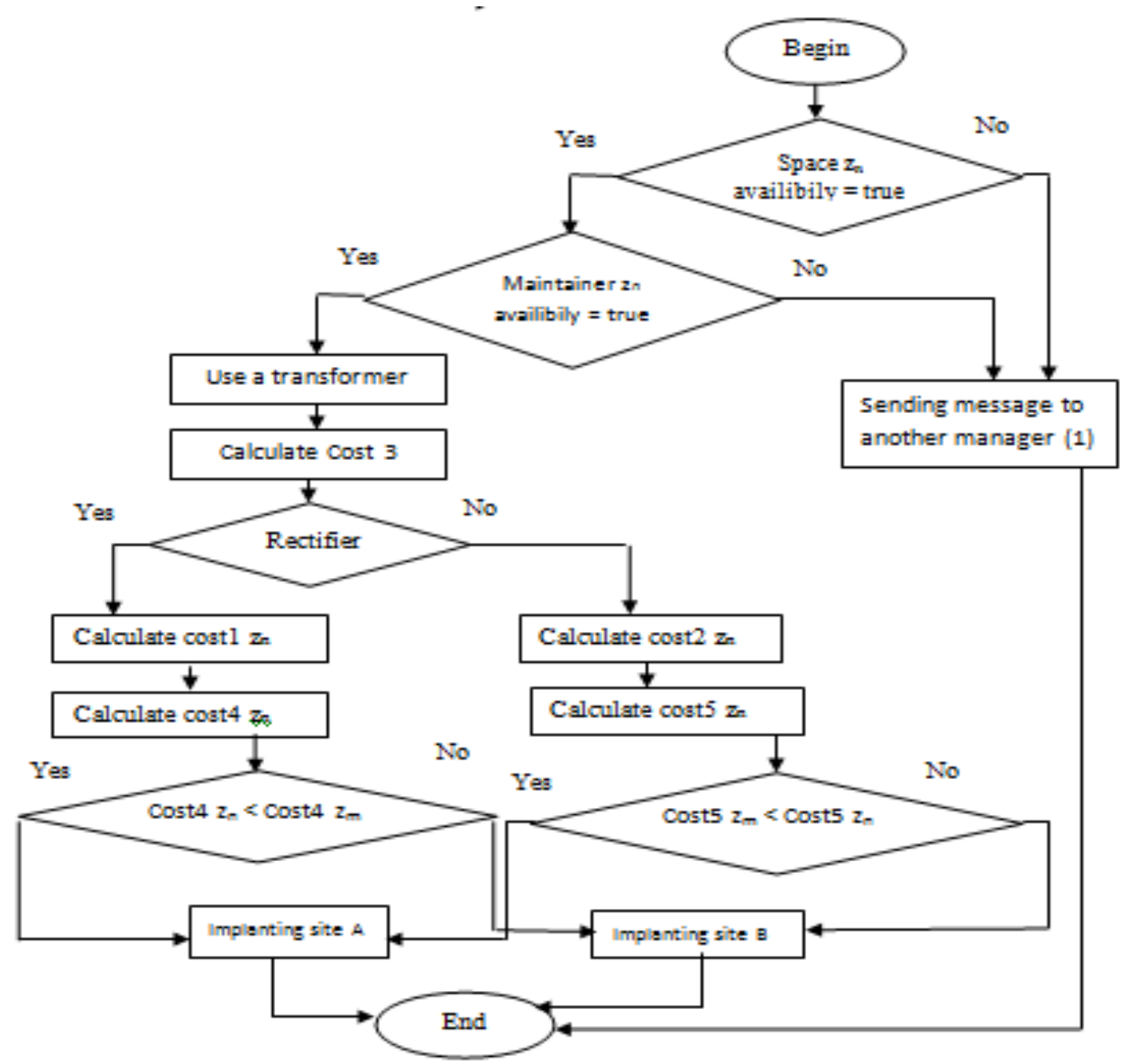

Fig. 12 Decision process corresponding to the second case

The cost is calculated following formula 3 in the case of only a transformer is needed:

$$
\text { Cost } 3=A C T+I C T+C C+T C T
$$

The second cost of this scenario is calculated by including the inverter and rectifier relative costs, like it is shown respectively in formulas 4 and 5:

$$
\begin{aligned}
& \text { Cost } 4=\text { Cost } 3+\text { Cost } 1 \\
& \text { Cost } 5=\text { Cost } 3+\text { Cost } 2
\end{aligned}
$$

Figure 13 shows the proposed control system.

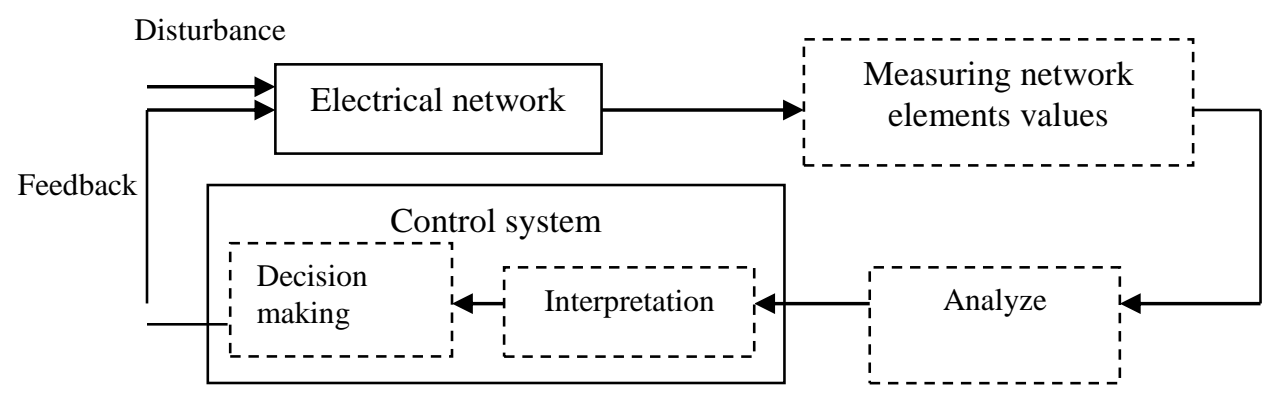

Fig. 13 The Proposed Control System 
Figure 14 shows different teams' members concerned by new sites implantations.

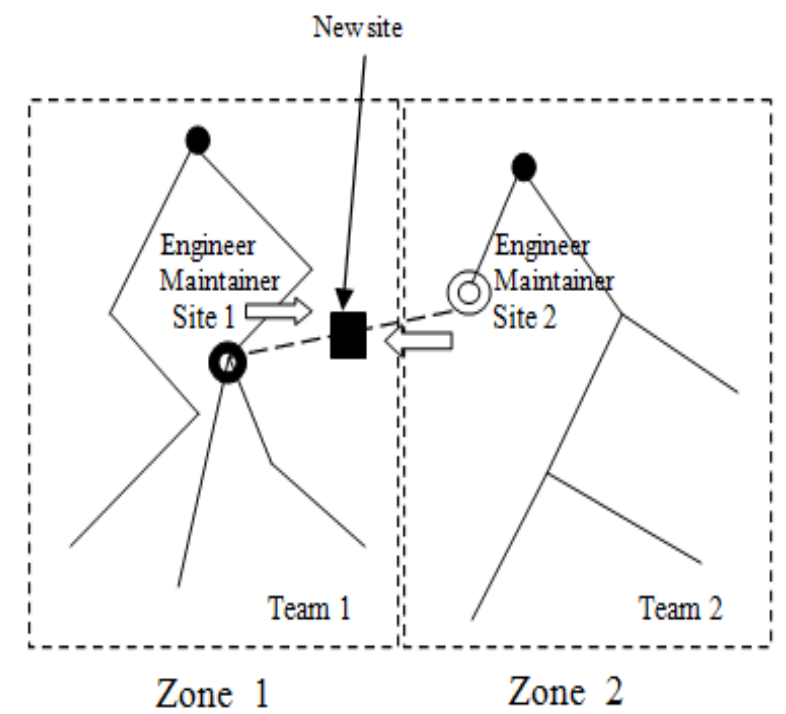

Fig. 14 Members concerned by implantation of a new site

\section{EXPERIMENTS}

As it was mentioned in section 1 , results concern two points:

\subsection{Structural Point of View}

A node corresponds to a site to be implanted, when a novel site is implanted, teams' structures should be modified. We suppose that concerned teams are situated in neighboring nodes in the aim to minimize transportation costs. Figure 15 shows the number of stakeholders (members) who can be concerned by new nodes (sites) implantations.

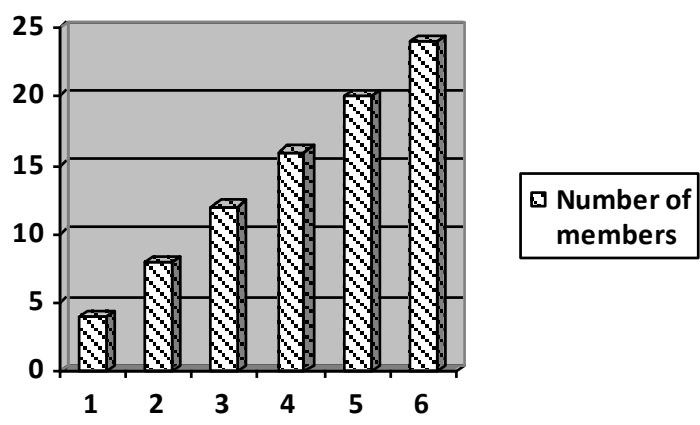

Fig. 15 Number of members who can be concerned by nodes implantations

We can see in Figure 14 that the number of members (engineers and maintainers) is proportional to the number of nodes to be implanted. Each stakeholder has a role in the global smart grid as it can be shown in Figure 6. For each operation of new implantation; the members must perform their respective tasks. If we take the example of two nodes implantation, there will be a maximum of eight members in concerned and adjacent zones that may be involved, as it can be shown in Figure 16. 


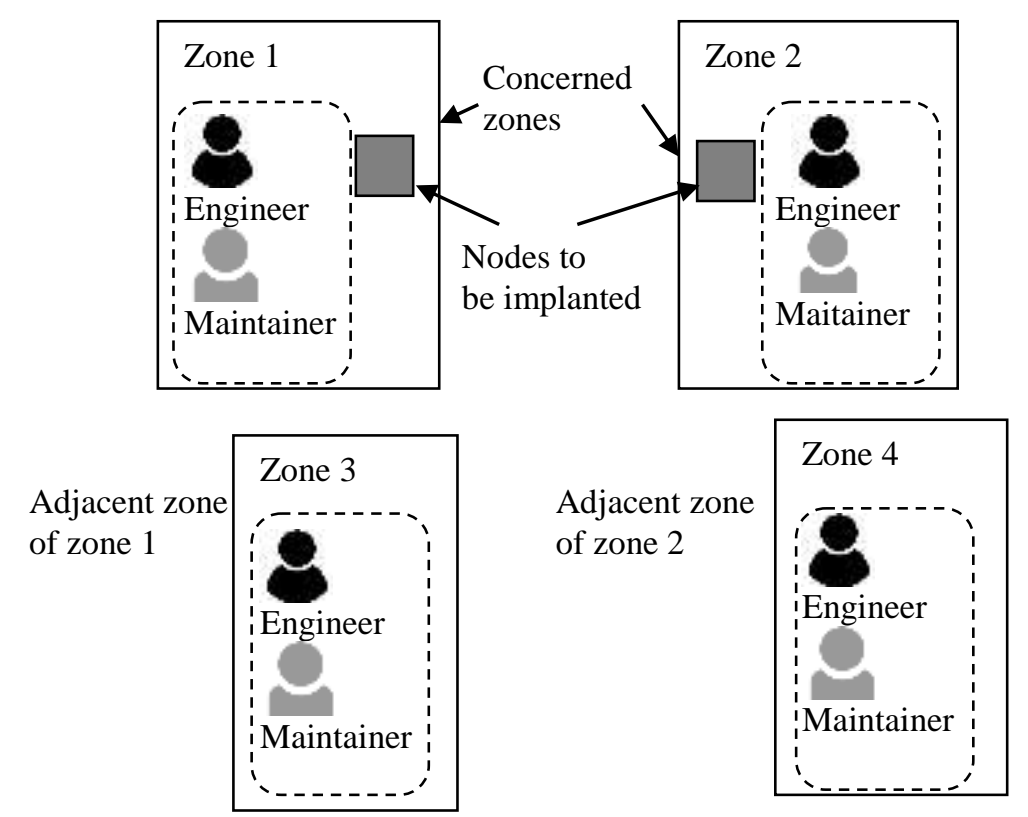

Fig. 16 Concerned Members by Two Nodes Implantation

\subsection{FUNCTIONAL POINT OF VIEW}

In this point of view, the managers' behaviors are taken into account. In Figure 17, solution 1 corresponds to the case where the manager of zone 1 uses the case based reasoning.

Solution 2 concerns the case where the manager of the first zone doesn't use the case based reasoning, the interaction of this solution is presented in Figure 7.

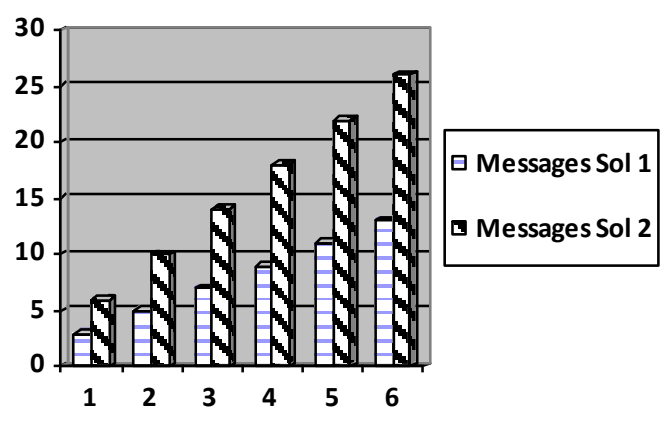

Fig. 17 Number of Messages Exchanged

Experiments show that for each solution, we have different number of messages exchanged between managers and other members of teams: the messages exchanged in solution 1 where the case based reasoning is used are less that messages exchanged in solution 2 relative to a classical decision making.

The difference can be explained by the fact that where the case based reasoning is used by a manager, this allows him to avoid asking some details from other participants (engineer), which reduces the number of messages exchanged.

Concerning implantation of one node, if we use the case based reasoning, the manager of zone 1 contacts the manager of zone 2 who sends a response ( 2 messages) and contacts 
engineer to execute tasks (one message); this interaction gives a total of three messages. Figure 18 shows the sequence diagram of the interactions.

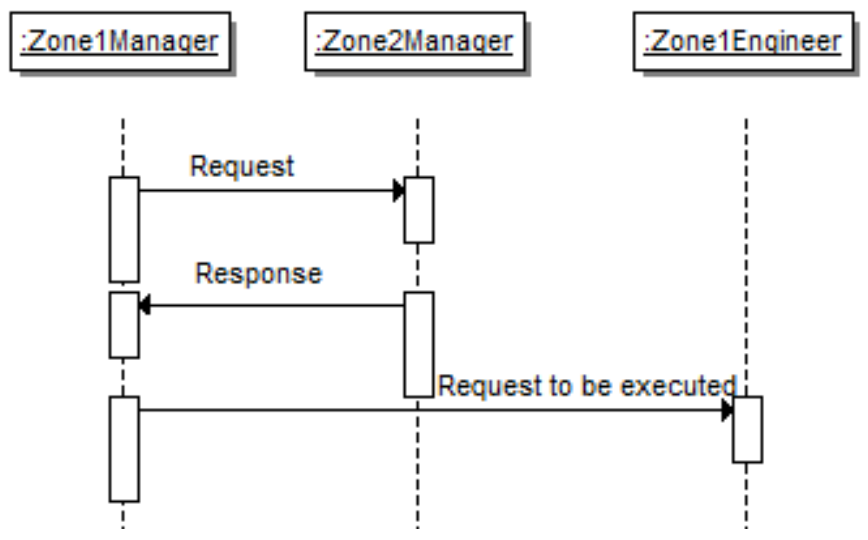

Fig. 18 Sequence Diagram of Managers' Interactions when using the CBR

If we use a solution without integrating the CBR, the manager 1 contacts at the first time the engineer of zone 1 (one message) and the manager of zone 2 (one message), the manager of zone 2 contacts the engineer (one message). The same principle is applied for implantation of more nodes.

Next section shows the position of this contribution.

\subsection{POSITION OF CONTRIBUTION}

Our contribution takes place in the way of the elasticity of a distributed structure (company):

Many aspects have been taken into account; the comparative study is shown in Table 3:

Table III. Position of the Contribution

\begin{tabular}{|l|c|c|l|c|c|c|c|c|}
\hline Reference & $\begin{array}{c}\text { Distributed } \\
\text { Energy } \\
\text { System }\end{array}$ & $\begin{array}{l}\text { Compare } \\
\text { availability } \\
\text { performance }\end{array}$ & $\begin{array}{l}\text { System } \\
\text { Heterogeneity }\end{array}$ & Cost & $\begin{array}{l}\text { Role of cloud in } \\
\text { elasticity }\end{array}$ & $\begin{array}{c}\text { Elasticity } \\
\text { metric }\end{array}$ & Scalability & Modeling \\
\hline$[1]$ & $\mathrm{X}$ & & & & & & & \\
\hline$[3]$ & & $\mathrm{X}$ & & & & & & \\
\hline$[4]$ & & & $\mathrm{X}$ & & & & & \\
\hline$[5]$ & & & & $\mathrm{X}$ & & & & \\
\hline$[6]$ & & & & & $\mathrm{X}$ & & $\mathrm{X}$ & \\
\hline$[7]$ & & & & $\mathrm{X}$ & & $\mathrm{X}$ & $\mathrm{X}$ & \\
\hline$[8]$ & & & & & & & & $\mathrm{X}$ \\
\hline $\begin{array}{l}\text { Proposed } \\
\text { approach }\end{array}$ & $\mathrm{X}$ & & $\mathrm{X}$ & $\mathrm{X}$ & & $\mathrm{X}$ & $\mathrm{X}$ & $\mathrm{X}$ \\
\hline
\end{tabular}

Table 3 shows that the aspect of distributed energy system is taken into account in this contribution including the heterogeneity of the global electrical system and costs calculation relative to the scalability of a global system when there is a need to increase electrical energy supplying. In this contribution elasticity metrics used concerns the number of exchanged messages and the number of partners concerned.

The next section presents some ideas concluded in this work and future eventual works. 


\section{CONCLUSION}

In this paper, we first propose an UML modeling of a distributed electrical system management, in the aim to show the importance of interaction and information sharing for the decision process. In a second time, the paper shows the use of the case based reasoning approach to solve the problem of the need of modification in an existing electrical system.

We also present the elasticity analysis in both of structural and functional points of view. Concerning the first point, the study shows in first that there is a direct effect between end users consumption and the global structure of an electricity provider company, of course, plus electricity consumption increase, plus the company must implant new electrical provider nodes, this case involves a management of new structure using the intervention of partners from different zones. The effect in a structural point of view is that the number of engineers and maintainers who may be concerned is proportional to the number of new nodes implantation.

Concerning the functional point of view, behaviors of managers were evaluated according to messages exchanges with other stockholders of their respective zones; the study shows that the use of the CBR reduces the managers' interactions.

As future contributions, the authors propose the study of message's complexity in terms of number and structure. The CBR module can be improved including other attributes relative to characteristics of electrical systems in addition to those used.

\section{REFERENCES}

[1] Jingcheng Gao, Yang Xiao, Jing Liu, Wei Liang, C.L. Philip Chen. A survey of communication/ networking in Smart Grids. Future Generation Computer Systems 28. (2012) 391-404.

[2] Henrik Lund, Anders N. Andersen, Poul Alberg Østergaard, Brian Vad Mathiesen, David Connolly. From electricity smart grids to smart energy systems - A market operation based approach and understanding. Energy 42 (2012) 96-102.

[3] Mhadhbi, Zeineb, Zairi, Sajeh, Gueguen, Cedric and Zouari, Belhassen. Validation of a Distributed Energy Management Approach for Smart Grid Based on a Generic Colored Petri Nets Model. Journal of Clean Energy Technologies, Vol. 6, No. 1, January 2018.

[4] Ma, Weiwu, Fang, Song, Liu Gang and Zhou Ruoyu. 'Modeling of district load forecasting for distributed energy system'. Review article. Applied Energy, Vol. 204, (October 2017) pp. 181-205. 15. doi.org/10.1016/j.apenergy.2017.07.009.

[5] Ait Si Larbi El Yasmine, Belalem Ghalem, Beldjilali Bouziane, Towards a scalability approach for risk mitigation in electrical systems, Int. J. Knowledge Engineering and Data Mining, Vol. 5, Nos. 1/2, 2018.

[6] Yuksel, Murat and Kalyanaraman Shivkumar. Elasticity Considerations for Optimal Pricing of Networks. Published in ISCC, 2003. DOI:10.1109/ISCC.2003.1214117

[7] Addabbo, Tommaso, Fort Ada, Mugnaini Marco and Vignoli Valerio. (November 2017) 'Distributed UPS control systems reliability analysis’. Original research article. Measurement, Vol. 110, pp. 275283. DOI: 10.1016/j.measurement. 2017.06.021.

[8] Liu Yishen. (2017) 'Estimating the Elasticity of Supply of Housing Space Rather than Units'. Original research article. Regional Science and Urban Economics, In press, accepted manuscript, Available online 28 October 2017. doi.org/10.1016/j.regsciurbeco.2017.10.013.

[9] Bakhat, Mohcine, Labandeira Xavier, Labeaga José M., López-Otero Xiral. (2017) 'Elasticities of transport fuels at times of economic crisis: An empirical analysis for Spain'. Original research article. Energy Economics, In press, accepted manuscript, Available online 24 October 2017. doi.org/10.1016/j.eneco.2017.10.019.

[10] Lehrig, Sebastian, Sanders Richard, Brataas Gunnar, Cecowski Mariano Simon Ivanšek and Polutnik Jure. (2018) 'CloudStore - towards scalability, elasticity, and efficiency benchmarking and analysis in Cloud computing'. Original research article. Future Generation Computer Systems, Volume 78, Part 1, pp. 115-126, January 2018. DOI: 10.1016/j.procs.2015.09.225.

[11] Beltrán, Marta, (2016) 'BECloud: A new approach to analyse elasticity enablers of cloud services'. Original research article. Future Generation Computer Systems, Vol. 64, pp. 39-49, November 2016. doi.org/10.1016/j.future.2016.05.014. 
[12] Cibrario Bertolotti, Ivan, Durante Luca, Seno Lucia and Valenzano Adriano. (2015) 'A Twofold Model for the Analysis of Access control policies in industrial networked systems'. Computer Standards \& Interfaces, 42, pp.171-181. doi.org/10.1016/j.csi.2015.05.002.

[13] Slade, Stephen, Case-Based Reasoning: A Research Paradigm, AI Magazine Volume 12 Number 1 (1991) (@ AAAI), 0738-4602/90/\$4.00 @1990 AAAI

[14] Ketler, Karen, Expert Systems with Applications. Volume 6, Issue 1, January-March 1993, Pages 3-8, https://doi.org/10.1016/0957-4174 (93) 90014-W, Available online 14 February 2003.

[15] Leake, David B., Case-Based Reasoning: Experiences, Lessons and Future Directions, Book, $1^{\text {st }}$ MIT Press Cambridge, MA, USA (C1996 ISBN:026262110X.

[16] Minor Mirjam and Marx Lutz. Case-Based Reasoning for Inert Systems in Building Energy Management; Proceedings of the International Conference on Case-Based Reasoning; Trondheim, Norway. 26-28 June 2017; pp. 200-211.

[17] González-Briones Alfonso, Prieto Javier, De La Prieta, Fernando, Herrera Viedma Enrique and Corchado, Juan M. Energy Optimization Using a Case-Based Reasoning Strategy. Sensors (Basel). 2018 Mar; 18(3): 865. Published online 2018 Mar 15. doi: 10.3390/s18030865.

[18] Humphreys Paul, McIvor Ronan, Chan Felix, Using case-based reasoning to evaluate supplier environmental management performance, Expert Systems with Applications. Volume 25, Issue 2 , August 2003, Pages 141-153., https://doi.org/10.1016/S0957-4174 (03) 00042-3.

[19] Kwon Ohbyung, Im Ghi Paul, Lee Kun Chang, 'MACE - SCM: A multi agent and case -based reasoning collaboration mechanism for supply chain management under supply and demand uncertainties', Expert Systems with Applications Volume 33, Issue 3, October 2007, Pages 690-705, , https://doi.org/10.1016/j.eswa.2006.06.015.

[20] electropedia [online] http://www.electropedia.org/iev/iev.nsf/display?openform\&ievref=601-01-26. Accessed in 23/11/2017.

[21] iec [online] http://www.iec.ch/whitepaper/pdf/iecWP-globalenergyinterconnection.pdf, Accessed in $23 / 11 / 2017$

[22] Giroire Frédéric, Modrzejewski Remigiusz, Nisse Nicolas, Pérennes Stéphane (2017) 'Maintaining balanced trees for structured distributed streaming systems'. Original research article. Discrete Applied Mathematics, Vol.232, pp. 176-188. 11 December 2017. doi.org/10.1016/j.dam.2017.07.006.

[23] Lambert, Douglas M. and Cooper Martha C. (2000) 'Issues in supply chain management'. Industrial Marketing Management, 29(1), pp. 65-83. DOI: 10.1016/S0019-8501(99)00113-3.

[24] Pham, T.H. Thi (2006). 'Influences de la production décentralisée sur la gestion des infrastructures critiques des réseaux de puissance'. Energie électrique. Institut National Polytechnique de Grenoble INPG. <tel-00174846>. (French).

[25] Watson, Ian D., 1999, 'Case-based reasoning is a methodology not a technology', Knowledge-Based Systems, vol 12, no. 5-6, pp. 303-308. 